\title{
Rebates, Matches, and Consumer Behavior ${ }^{*}$
}

\author{
Douglas D. Davis ${ }^{+}$and Edward L. Millner \\ Department of Economics \\ Virginia Commonwealth University \\ Richmond VA 23284-4000
}

8 September 2004

\begin{abstract}
* We thank, without implicating, Catherine Eckel, Phillip Grossman, David Urban, and participants in a session entitled "Eliciting Preference and Attitudes" at the 2003 Southern Economics Association Meetings for their helpful comments. We also gratefully acknowledge financial support from the National Science Foundation and the Virginia Commonwealth University School of Business Faculty Excellence Fund. Experimental data, and an unpublished appendix are available at http://www.people.vcu/ ddavis
\end{abstract}

+ Corresponding author. dddavis@vcu.edu. (804) 828-7140, (804) 828-1719 (fax) 


\title{
Rebates, Matches, and Consumer Behavior
}

\begin{abstract}
An experiment conducted to examine the effects of different discount formats on consumer purchases is reported. Participants made a series of purchase decisions for chocolate bars given (a) "rebates" from the listed price, (b) "matching” quantities of chocolates for each bar purchased, and (c) simple price reductions. Contrary to standard theoretical predictions, and consistent results in the context of charitable contributions by Eckel and Grossman (2003), we find that participants purchase significantly more chocolate bars under a "matching" sales format than under a comparable "rebate” format. Inattention to the net consequences of decisions, as well as some "rebate aversion”, explain the preference for matching discounts.
\end{abstract}

JEL Classification: C91, D11, D46

Key words: Consumer Behavior, Experiment, Discount Formats 
Evil Dog Consultant: “Don’t sell your new product for $\$ 29$. Offer it at $\$ 1,000,029$ with a rebate of $\$ 1,000,000$. People will think it’s a great bargain when in fact it's just a huge inconvenience. Foolish Boss: "And all we need is one person to forget to mail in the rebate forms"

Evil Dog Consultant. "We'll target the lazy rich." Dilbert Cartoon.

\section{Introduction.}

Standard economic theory suggests that participants should be indifferent to the format of a price reduction. Abstracting from issues of quality, convenience and variety, a good's effective sales price should be the only relevant determinant in an optimizing decision-maker's purchase decision. However, as is clear from a stroll through any retail outlet or a glance at the advertising section of any newspaper, retailers do not format price reductions uniformly. In addition to simple price discounts, retailers often promote products with a variety of matching promotions, such as "buy one, get one free." Retailers also frequently promote price reductions as rebates, either offered at the point of purchase or on a delayed (mail-in) basis. Retailers clearly have reasons to vary price discount formats that are independent of direct consumer responses to the different formats. A "two for the price of one" matching discount, for example, may represent a form of declining block pricing, a format that may be particularly useful for exhausting bulks of perishable products. Similarly, retailers may offer rebates in an effort to price discriminate between the price sensitive customers, who send in the rebate coupon, and less price sensitive customers, who do not. ${ }^{1}$

Recent experimental evidence in the context of charitable goods contributions suggests that consumers may view these different sales formats quite differently. Eckel and Grossman (2003) report much higher charity receipts under a "matching subsidy" condition, where the experimenter matched any individual contributions at a pre-announced rate, than under a comparable "rebate subsidy" condition, where a portion of contributions were rebated back to participants after they made their decisions. Eckel and Grossman offer no definitive explanation for the larger receipts colleted under the matching subsidy condition. However, they suggest that

\footnotetext{
${ }^{1}$ Other more psychological reasons may also prompt the use of rebates. Rebates, for example, may offer retailers a way to offer short term price reductions without undermining whatever perception of "value" that may be associated
} 
“cooperation" and "rewards" framing effects may explain their observed behavior. The matching subsidy, they suggest, may create a "cooperation" frame, in which the knowledge that others are also contributing stimulates contributions.

In a related subsequent experiment Davis, Millner, and Reilly (2004) replicate the finding that matching subsidies generate substantially higher charity receipts than theoretically comparable rebate subsidies. However, in a series of treatments designed to shed light on the superior stimulative effects of matching subsidies Davis, Millner and Reilly find that the vast bulk of decisions are consistent with "constant contribution” behavior. Most non-optimizing participants contribute either exactly the same gross amount under all conditions, or contribute the same gross amount on average.

A natural and important extension of this research regards examining the impact of subsidy schemes on buyer behavior in more standard retail contexts Discounts on consumer goods presents a context that is at once less abstract than charitable contributions, and one with which the relevant participant population (college undergraduates) typically has had considerably more experience. Any college student undoubtedly faces with frequency both "buy one, get one free" and "instant rebate” sales promotions. An absence of discount format effects in a more standard private goods consumption context would suggest that a failure of many individuals to appreciate the relatively subtle problem of understanding the net effects of their contributions drives the observed superior stimulative effects of matching contributions in the charitable contributions context. On the other hand, to the extent that student purchase decisions are sensitive to matching and rebate discount formats, discount formatting effects may be both more pervasive and more economically important than previously imaged.

This paper reports an experiment conducted to evaluate the effects of different pricereduction formats on purchase decisions for a private consumer good. More specifically, we give participants the opportunity to purchase quantities of chocolate bars under different prices and under matching and rebate discount formats. Ours is certainly not the first attempt to assess "homegrown" preferences for specific consumer goods. To the contrary, efforts by economists to exploit controlled conditions to evaluate demand theory and predictions regarding the theory of revealed preference date at least to the classic study of purchase decisions by patients in a

with a price. Experimental evidence from the marketing literature supports this conjecture (see e.g., Folkes and Wheat, 1995). 
commissary at a women’s psychiatric hospital by Battalio et. (1973). Other related studies include food pellet choices by rats and pigeons (summarized in Kagel et. al., 1995), preference choices for bags of chips and juice boxes by elementary school children (Harbaugh, Krause and Berry, 2001), and consumer preferences for different types of beef packaging Hoffman et al. (1993) and for various types of orange juices (Février and Visser, 2004). ${ }^{2}$ The present study differs from this previous research in that we focus primarily on the effects of changes in the format of identical prices, rather than the consistency of choices across different prices.

By way of overview, we find that participants purchase considerably larger quantities of chocolate under a matching quantity condition than they purchase under either equivalent straight price reductions or under point-of-purchase "instant” rebates. Analysis of decisions suggests that, as was the case for charitable contributions, an inattention to the consequences of the different discount formats drives a substantial portion of the apparent preferences for quantity matching discounts. However, unlike charitable contributions, a distrust or dislike of rebates also explains some of participants’ apparent preference for matching discounts in this private goods context. Although we cannot extend results from our laboratory study directly into retail contexts, the combined effects of inattention to the discount format, and a dislike of rebates work in the same direction, suggesting that retailers should consider carefully the use of rebates. We organize our discussion as follows. Section 2 below explains the experimental design and procedures. Section 3 describes experimental results and a short $4^{\text {th }}$ section concludes.

\section{Experiment Design and Procedures}

2.1. Experiment Design. Our experiment uses a variant of the modified dictator game structure used previously by Eckel and Grossman (2003) and Davis, Millner and Reilly (2004). ${ }^{3}$ Here we extend the investigation of matching and rebate sales formats to private goods by giving participants the opportunity to "spend” or "hold” of \$5 of their own money on chocolate bars under a series of different price and discount format conditions. To ensure that participants had disposable income at the time they made decisions, we presented the problem to interested participants after they had been paid for participation in a previous, unrelated experiment. To

\footnotetext{
${ }^{2}$ Prominent findings of this line of research include (a) that (income compensated) quantities of a given good purchased tend to increase as the price falls and (b) nevertheless, many individuals violate the basic transitivity conditions underlying the Generalized Axiom of Revealed Preference (“GARP”).
} 
overcome the well known "reluctance to trade", documented, for example, by Kahneman, Knetsch and Thaler (1990), all prices are set very substantially below the current retail price.

The sample Allocation Decision Sheet, presented as Figure 1 summarizes the set of possible allocations. Starting from a reference price of $\$ 0.50$ per bar (BASE-50), participants made decisions regarding successively lower prices of $\$ 0.33$ (BASE-33) and $\$ 0.25$ (BASE-25) 4 . For each price reduction we also presented participants with a pair of reductions under comparable rebate and matching subsidies. For example, given a price of \$.50, both a matching sales opportunity to get one bar free for each bar purchased (MATCH-25) or a rebate option of purchasing bars for \$.50, but getting a 50\% refund for each bar purchased (REBATE-25), generate an effective net price of $\$ .25$. Similarly, starting from a reference price of $\$ .50$, both a 3 for the price of 2 matching subsidy (MATCH-33) and a 33\% rebate (REBATE-33) are equivalent to a net sales price of $\$ 0.33$. To the extent that individuals make decisions consistent with the theory of demand, purchase quantities should at least weakly increase as the price falls ( $q_{\text {BASE-25 }} \geq q_{\text {BASE-33 }} \geq q_{\text {BASE-50 }}$ ) Further, to the extent that individuals are insensitive to the price discount format $q_{\text {BASE-25 }}=q_{\text {MATCH-25 }}=q_{\text {REBATE-25 }}$ and $q_{\text {BASE-33 }}=q_{\text {MATCH-33 }}=q_{\text {REBATE-33. }}$. We evaluate decisions regarding rebates and matching subsidies in light of previous results. Specifically, to the extent that matching price discounts elicit larger net effects than rebates, we expect to observe $q_{\text {MATCH-25 }}>q_{\text {REBATE-25 }}$ and $q_{\text {MATCH-33 }}>q_{\text {REBATE-33. }}$

2.2. Experimental Procedures. Data was collected from student volunteers, as they completed an unrelated experiment. Just prior to paying participants at the conclusion of the initial experiment, a session monitor announced that a short second, experiment would follow. The monitor stated that the additional experiment will take approximately 20 minutes and that for their efforts subjects would receive an additional \$3. Participants desiring to leave were privately paid their earnings for the previous experiment and exited the laboratory. The remaining participants also privately received their earnings, plus $\$ 3 .^{5}$ After the payment of all participants, a session monitor distributed to each of the remaining participants, who were seated in visually isolated booths, a packet containing instructions, an Allocation Decision Sheet, and a

\footnotetext{
${ }^{3}$ Andreoni and Vesterlund (2001), and Andreoni and Miller (2002) first developed this basic framework. However, in these earlier papers only the price of contributions, and not the discount format was altered.

${ }^{4}$ The descriptive labels appearing in Figure 1 and in the text are used to facilitate the presentation. Non-suggestive single letter identifiers were used in the experiment.

${ }^{5}$ Earnings for the initial (1 hour) experiment averaged about $\$ 21.00$ and ranged from $\$ 9.00$ to $\$ 55.00$.
} 
questionnaire that elicits qualitative responses to a pair of hypothetical sales promotions; as well as information regarding the clarity of instructions and procedures. ${ }^{6}$

The directions, which the session monitor read aloud, explained that participants were to make a series of seven allocation decisions and that upon completion of the allocation sheets one randomly selected allocation decision for one randomly selected participant will be implemented. In each decision allocation problem, participants decided on the amount of up to $\$ 5$ of their own money they wish to spend on 1.25 oz. Ghiradelli chocolate bars, under the price and the "instant" rebate or matching subsidy condition printed in column (b) of the allocation sheet. ${ }^{7,8}$ Participants completed the allocation decision sheet by entering an amount to pass and an amount to hold in columns (c) and (d) of each row in the sheet, and then the questionnaire. To avoid possible sequencing effects we randomized the order of problems on each Allocation Decision Sheet. When all participants were finished, the monitor randomly selected one participant. The selected participant then chose one card from a stack of seven cards with letters identifying each decision. The participant then exchanged chocolate bars for cash, as directed by their response to the selected decision on their Allocation Decision Sheet, and was dismissed. ${ }^{9}$ We note that our use of a well-known product, offered at prices well below the market price, in a “one-shot” decision context where payments are based on a single decision submitted simultaneously by all participants largely conforms with the "best practices” for eliciting homegrown values identified by Harrison, Harstad and Rutström (2004). ${ }^{10}$

\footnotetext{
${ }^{6}$ Instructions appear as Appendix A. To mitigate possible concerns regarding delayed rebates, the instructions explained clearly (with an illustrative example) that any rebates would be processed immediately. Also, we collected the same socio-demographic information collected in previous studies. Socio-demographic characteristics have not been important in this literature, and we do not here analyze them. A copy of our questionnaire appears in an unpublished appendix.

${ }^{7}$ At the time of the experiment 1.25 ounce Ghiradelli chocolate bars retailed for $\$ 1.37$ (including sales taxes). We offered the bars at effective sales prices ranging between $\$ .25$ and $\$ .50$ per bar.

${ }^{8}$ Procedures differed slightly in two of the sessions. In these sessions, a randomly selected allocation decision was implemented for each of the participants, instead of for one selected subject. Further in these two cases, participants were allowed to spend up to $\$ 10$ rather than $\$ 5$. A total of 16 subjects participated in these two sessions. These minor procedural deviations do not affect predicted behavior, and results in these sessions do not differ identifiably decisions in the remaining sessions.

${ }^{9}$ To help mitigate possible preference effects for particular types of chocolate, participants could take their chosen allotment in any desired combination of dark chocolate and/or milk chocolate with almond bars

${ }^{10}$ As Harrison, Harstad and Rutström (2004) point out, experimenters wishing to elicit subjective values should adopt practices that minimize biases induced by field price censoring, affiliated beliefs about field prices and affiliated beliefs about the quality of the commodity. The use of artificially low laboratory prices for a well-known commodity mitigates potential biases due to field-price censoring (although such a practice does expose the experimenter to potential arbitrage by participants). Using a one-shot institution prevents participants from basing
} 
A total of 103 people made decisions in a series of nine different sessions. Responses to part (c) of the questionnaire indicate that participants generally understood procedures. The mean agreement to the question "the instructions for the experiment were clear and easy to follow” was 4.28 on a 5-point scale (standard deviation of 0.93 ). This mean clarity ranking exceeds slightly the mean response to a comparable question reported by Eckel and Grossman (2003), as well as the clarity ratings in two of the three treatments reported by Davis, Millner and Reilly (2004).

\section{Results}

3.1. Overview. Table 1 summarizes mean purchase decisions for the 89 participants who reflected a willingness to purchase at least one chocolate bar under at least one price/subsidy condition. ${ }^{11}$ Inspection of the table reflects clearly a reluctance to trade (or a distaste for relatively high-quality chocolates). Despite a 63\% discount from the (tax inclusive) retail price participants purchased only 2.46 bars on average at a price of $\$ 0.50$ per bar. Even at a price of \$0.25 per bar, participants purchased slightly less than 5 bars on average. Nevertheless, as is evident from scanning down the columns of the Table, in each price format, individuals do tend to purchase significantly more on average as the price falls. As indicated by the double asterisks appearing aside each entry, purchase quantities increased significantly for each price reduction, save one (using a t-test, $\mathrm{p}<.001,1$-tailed test). The exception is the $33 \%$ rebate from a price of $\$ 0.50$, shown in column (3). In this case, although mean quantity again increased, from 2.46 to 2.75 , the significance of the increase is only marginal ( $\mathrm{p}<.10$, one-tailed test).

However, comparing entries across columns in Table 1 suggests that individuals were not indifferent to the discount format. Relative to the no-subsidy decisions, summarized in column (1), matching discounts, listed in column (2) tend to increase purchases, while rebates, shown in

value decisions on the purchase choices of others, thus avoiding potential biases attributable to affiliated beliefs about field prices, or affiliated beliefs about the quality of the commodity.

11 We exclude from analysis the decisions of the 14 participants who never purchased any chocolate bars, under any price/subsidy condition. While participants who do not like chocolate act in a fully rational way when the make no purchases, their choices offer no insight into reactions either to price reductions, or to different price formats. Including the omitted decisions does not affect any of our primary conclusions. Tables parallel to Tables 1 and 2 that include decisions of all 103 participants appear as tables A1 and A2 in an unpublished appendix. More generally, we think it interesting to observe the very substantial loss in control that would be associated with using a very popular good, such as chocolates for purposes of motivation, rather than induced value. Clearly it is not the case that "everyone likes chocolate." In addition to the 14 participants who made no purchases, another 14 indicated that they did not like chocolate, or that they truncated their purchases for health or dietary reasons. 
column (3), tend to reduce purchases. Even more prominent, comparing across columns (2) and (3) notice that individuals purchase very considerably more under a matching condition than under a comparable rebate condition. At a price of \$0.33 per bar, participants purchased 3.94 bars under a matching condition, but only 2.75 bars under a rebate condition. Similarly, at a price of \$0.25 per bar, participants averaged 5.17 bars under a matching condition, but only 3.60 bars under a rebate condition. Table 2 presents results of matched-pair $t$-tests across entries in the columns of Table $1 .^{12}$ As seen in column (1), matching discounts tend to increase purchases relative to straight price reductions, and, as seen in column (2) straight price reductions tend to elicit higher quantities than rebate discounts. But combined, matching discounts uniformly elicit significantly higher quantities than a comparable rebate, as seen in column (3) $(\mathrm{p}<.01$, direction not predicted). These observations form our first finding.

Finding 1: Within discount formats, quantity demanded moves inversely with the net sales price. However, quantity purchases vary significantly across formats. Most prominently, at any price, net purchase quantities are higher for a matching sales format than for a comparable rebate sales format.

\subsection{Understanding the Different Responses to Matches and Rebates. The large and persistent} differences observed here between purchases of a private good under matching and rebate subsidy conditions parallel results observed in a charitable contributions context by Eckel and Grossman (2003) and by Davis, Millner and Reilly (2004). Unlike this previous research, however, it is not here plausible to attribute the different responses elicited by the different discount formats to "contributions” or "rewards” framing effects. Individuals here decide to purchase chocolate bars, presumably for their own consumption. The fact the monitor does or does not fail to assist in this process is simply irrelevant. ${ }^{13}$

Davis, Millner and Reilly (2004) argue that in a charitable goods context, inattention to the net consequences of match and rebate subsidy conditions explains much of the anomalous

\footnotetext{
${ }^{12}$ Notice that, unlike Table 1, we use 2-tailed tests in Table 2. For the comparisons reported in Table 1 theory suggests a directional prior (e.g., that quantity moves inversely with price), making a one-tailed test appropriate. In contrast, for the comparisons reported in Table 2, theory suggests no expected deviation (e.g, different price formats should elicit the same quantities, provided that each format generates the same effective price). Thus 2-tailed tests are appropriate.

13 Davis, Millner and Reilly (2004) also report a treatment conducted in a private contributions context, where participants make allocation decisions between cash and a riskless "investment" alternative with a concave payoff function. Davis, Millner and Reilly also observed larger net contributions under matching subsidies in their “investment context” treatment. However procedures used here are considerably more transparent.
} 
behavior. In particular, many people "passed" exactly the same number of dollars to a charity under both matching and rebate subsidy conditions. Behavior of this sort is perhaps rather unsurprising in the context of charitable contributions, where often relatively inexperienced participants make one-shot decisions for a rather abstract good. However, as the histograms in the two panels of Figure 2 illustrate, such "constant (gross) contributions" behavior clearly extends to the case of private goods. Each panel of Figure 2 plots the "Pass Ratios" for each individual under comparable matching and rebate subsdy conditions. Formally, define the Pass Ratio for individual $i$ at effective price $P$ as $r_{i}^{P,}=X_{i}^{P, M} / X_{i}^{P, R}$ where $X_{i}^{P, M}$ denotes then number of dollars passed (and spent) on candy bars under a match condition, and $X_{i}^{P, R}$ denotes the number of dollar passed for candy bars under the rebate condition (prior to the rebate). Given the effective price of candy bars is $\$ 0.25$ (e.g., under the MATCH-25 or the REBATE-25 conditions), an individual responds equivalently to each discount format when $r_{i}^{25}=.5$. For example, with a 2-1 match, passing $\$ 1$ results $\$ 1$ spent on 2 candy bars. With a $50 \%$ rebate, passing \$2 again results in a \$1 expenditure after rebates, and 2 candy bars. Reasoning similarly, given an effective price of $\$ 0.33, r_{i}^{33}=.67$. Comparing across the panels in Figure 2, observe the very large density spikes at 1 in each chart, indicating that rather than responding to the price incentives implicit in the different subsidy types, many participants passed exactly the same gross amount under comparable conditions. ${ }^{14}$

In a charitable goods context, Davis, Millner and Rielly (2004) further observe that participants who were neither optimizers nor followed a simple fixed constant contribution rule exhibit aggregate behavior consistent with a stochastic variant of constant contributions. These “other" participants, donated roughly the same gross amount for each decision on average. Further, both the number and symmetry of deviations above and below the constant contributions level in this previous paper suggest that their deviations were random. Closer consideration of the Pass Ratios shown in Figure 2 suggests that something other than random deviations from constant contribution behavior may drive a relative preference for matching subsidies in the case of private goods, particularly as the value of the rebate/matching subsidy becomes small. Excluding in Figure 2 the Pass Ratio decisions consistent with optimization, the distribution of

\footnotetext{
${ }^{14}$ Notice from the interval midpoints shown in the horizontal axis of Figure 2, that we use a ratio scale. The ratio scale attenuates graphically the effects bias toward large spending ratios. A gross contribution of $\$ 1$ under a matching subsidy and $\$ 2$ under comparable rebate subsidy generates a spending ratio of $1 / 2$. The reverse generates a spending ratio of 2 , four times farther from 1 than $1 / 2$.
} 
remaining "non-optimizing” decisions in each panel is right-skewed. In the upper panel of Figure 2, the difference is relatively subtle. Notice in the upper panel that while roughly as many non-optimizing deviations appear above 1 as below 1, those Pass Ratios below 1 line cluster about optimal behavior (.5). In contrast, most of the observed Pass Ratios in excess of 1 appear in the "more" category, where participants who purchased some bars with a matching subsidy tended to purchase nothing with a comparable rebate. A relative preference for matching subsidies is more clearly apparent in the lower panel of Figure 2. Here the bulk of nonoptimizing deviations involve Pass-Ratios in excess of 1, and a large density spike appears in the “more” category, where participants make a positive purchase with a matching subsidy, but no purchase at all with a comparable rebate.

Quantitative support for these observations appears in Table 3. Notice in column (1) of Table 3 that when the effective discount is $50 \%$, somewhat more observations fall below 1 (21) than in excess of 1 (14). Using a $\chi^{2}$ test, however, this difference not significant $(\mathrm{p}<0.24)$. Nevertheless, the distribution of these differences is asymmetric (and right-skewed), as summarized in the bottom row of column (1) (K-S test, reject symmetry at $\mathrm{p}<.001) .{ }^{15}$ Column (2) summarizes information regarding the distribution of non-optimizing decisions when the effective discount is 33\%. Notice in this case that far more Pass Ratios exceed 1 (36) than fall below 1 (19), a difference that is easily significant, using a $\chi^{2}$ test $(\mathrm{p}<.0025)$. Perhaps unsurprisingly, we may also conclude that the distribution of deviations is asymmetric (K-S test rejects symmetry, $\mathrm{p}<.026$ ). Pooling decisions for the different effective prices (column (3)), notice that while the number of positive and negative deviations from 1 do not differ significantly $(\mathrm{p}<.44)$, we can again reject the null hypothesis that the distribution of deviations above and below 1 is symmetric $(\mathrm{p}<.011)$.

In an effort to gain some insight into generally held perceptions of rebate and matching discounts, as part of our questionnaire we elicited both specific and open-ended responses to a pair of hypothetical scenarios. Each scenario paired a good with a buy-one-get-one-free matching subsidy with an otherwise similar good sold under a 50\% rebate subsidy. In the first question, we attempted to create a scenario where the buyer wanted only a unit of the good. We asked the following:

\footnotetext{
15 The listed K-S test statistics compare non-optimizing Pass-Ratios below 1 with the inverse of non-optimizing Pass-Ratios above 1. Under the null hypothesis of symmetric deviations these distributions do not differ.
} 
Scenario 1: The lease on your apartment is ending and the landlord is about to make a final inspection before giving your security deposit back to you. You notice that a 150-Watt light bulb in the kitchen is burned out and go to the store to purchase a replacement. The store sells two brands of 150-Watt bulbs, "BrightLite" and "EverGlow". "BrightLite" is offering a rebate of half-off the purchase price to be redeemed at the register. "EverGlow" is offering a two for one special. Assuming that the products are perfect substitutes, which one would you purchase? Why?

Given a need for only a single unit, otherwise indifferent respondents should prefer the rebate subsidy. In a second question, we created a scenario where large quantities of a product were needed.

Scenario 2: You and your friends are having a graduation party and you have been assigned the duty of buying potato chips. A large number of guests are expected so you need to purchase 20 bags. You go shopping at the local grocery store for chips. First, you see that "Idaho's Best" is having a 2 for 1 special. The comparable brand, "Idaho's Finest," has attached to it a coupon redeemable at the checkout for half off the regular price. Which one do you choose? Why?

Under this condition, participants should express indifference between the two discount formats. Further, barring any underlying preference, the choice of matching and rebate discounts should be roughly balanced. The upper portion of Table 4 lists frequency distributions of indicated preferences in each scenario. ${ }^{16}$ The results are striking, and clearly suggest an aversion to rebates. In the second scenario, where no obvious reason for a discount format preference exists, only $22 \%$ of respondents indicated indifference. Further, non-indifferent responses reflect a solid preference for matching subsidies. Four times as many respondents indicated that they preferred a matching discount format to a rebate format. Even in scenario 1, where rebates should be strongly preferred notice that fully $28 \%$ of respondents indicated a preference for a matching discount format.

Explanations that occurred with a frequency sufficient to be classifiable are listed at the bottom portion of Table 4. As reflected in the first row below the “justification” heading, in Table 4, the differing discount formats clearly confuse some participants. Of the total respondents who justified their choices, 9\% in scenario 1 and 16\% in scenario 2 indicate that the two discount formats generated different effective prices. But, further examination of responses

\footnotetext{
${ }^{16}$ One participant did not submit answers to the hypothetical scenarios. Therefore, the number of observations is 102.
} 
indicates that factors beyond simple confusion are at play. In particular, 26\% (scenario 1) and $38 \%$ (scenario 2) of respondents who attempted to justify their decisions express an aversion to rebates. The explanations given by such "rebate averse” respondents are illuminating. Typical themes include conjectures that redeeming the rebate will take time or involve "hassle", ${ }^{17}$ that they may forget to use the rebate coupon, and that they dislike being identified as someone who uses rebate coupons.

These responses suggest that many participants may have avoided the use of laboratory rebates due to unpleasant experiences with rebates in natural contexts. Many participants view rebates, even those in the form of a coupon redeemable at check out, less certain and more troublesome, than matching subsidies. These observations are the basis of our second, and final finding.

Finding 2: “Constant (Gross) Contribution” behavior explains a considerable amount of the tendency for matching discounts to generate higher sales than rebate discounts. Nevertheless some "rebate aversion" may also contribute to the lower sales generated with rebate discounts, particularly when the rebate is small.

In retrospect, we find an aversion to rebates is unsurprising. Casual empiricism suggests that rebate aversion is both broad and fairly deep. ${ }^{18}$ Further, recent enforcement actions by the Federal Trade Commission against CompuServe, America On Line, and other sellers of computer products suggest that lengthy delays in the processing of rebates, and outright deception may also explain some of the disaffection with rebates. ${ }^{19}$ However, we do find it interesting that this rebate aversion is much more clearly evident in a private goods context. An analysis of Pass-Rates for in two charitable contributions treatments reported by Davis, Millner and Reilly (2004) that parallels the preceding analysis suggests no obvious "rebate aversion.”20

\footnotetext{
${ }^{17}$ Many respondents indicate that redeeming the instant rebate coupons would lengthen the check-out process.

${ }^{18}$ A Google search of the term "false rebates" generated some 74,000 hits, headed by websites filled with pages of complaints against leading retailers, includes Staples, Best Buy and Circuit City. See ConsumerComplaints.com and BadBusinessBureau.com. Of course, not all of these complaints involve delay or fraud (Indeed, many may be unjustified). However, they do collectively suggest considerable animosity against rebates

${ }^{19}$ See, in particular “AOL and Compuserve Settle FTC Charges of Unfair Practices”, FTC Release September 23, 2003.

${ }^{20}$ In the two charitable contributions treatment reported by Davis, Millner and Reilly, non-optimal Pass-Rates appeared to be "noise" about the constant contribution level. In each treatment, roughly the same number of deviations above 1 and below 1 were observed. Further, in each treatment the null hypothesis that "non-optimal" decisions were symmetrically distributed about the constant contribution level of 1 could not be rejected. Interestingly (and consistent results presented here), Davis, Millner and Reilly do find some evidence of rebate aversion in a third, "investment frame" treatment.
} 
Similarly, Eckel and Grossman (2002) report an experiment where participants could choose between rebate subsidies or matching subsidies for charitable contributions. They find no preference for one subsidy form over another, although, consistent with the other studies, participants make higher net contributions with the matching subsidy.

\section{Concluding Remarks}

This paper establishes that the preference for matching subsidies (or discounts) over rebates reported in a charitable contributions context by Eckel and Grossman (2003) extends to purchase decisions for private goods. To a large extent, “constant contribution” behavior, or an inattention to the net consequences of matching and rebate discounts drives much of the observed results. However, and unlike the charitable goods context, some evidence of a "rebate aversion" is also apparent, particularly when the rebates are fairly small.

At least in part, consumer aversion to rebates is quite likely an endogenous consequence of the reason retailers offer rebates. Rebates are a form of price discrimination that not only separates price-sensitive buyers who use coupons from less sensitive buyers who do not use the coupons, but they also discriminate against those consumers who forget or misplace their coupons, as well as against the many consumers who perceive the costs of coupon processing to be unacceptably high.

Despite general consumer distaste for rebates, retailers will likely find it profitable to offer them until the rents associated with consumers who do not process their rebate coupons no longer outweighs the sales foregone from a given price discount which is largely ignored because the discount is offered as a rebate. Nevertheless, to the extent the results were observe here have any external validity, retailers should use rebates with some caution. "Constant contribution" behavior, caused by an inattention to the net consequences of different sales formats, and rebate aversion work in the same direction and tend to make quantity matching discounts, as well as straight price reductions, more effective discount formats.

Future work in this area remains. Perhaps most the most important task is to assess the resilience of these discount format preferences. Our next step will be to conduct a set of experiments in which values are induced, as in a standard experimental context. This would allow for more refined examination of the relationship between the quantities purchased under 
differing price and subsidy conditions. In particular, one could determine which conditions, if any, result in the theoretically correct level of purchases. Further, use of a standard induced demand framework would also allow for task repetition, a feature that would allow for examination of the resilience and persistence of rebate aversion. 


\section{References}

Andreoni, James and John Miller (2002) “Giving According to GARP: An Experimental Test of the Consistency of Preferences for Altruism”, Econometrica 70, 737-757.

Andreoni, James and Lise Vesterlund (2001) "Which is the Fair Sex? Gender Differences in Altruism”, Quarterly Journal of Economics 116, 293-312.

Battalio, Raymond, C., John H. Kagel, Robin C. Winkler, Edwin B. Fisher, Robert L. Basemann and Leonard Krasner (1973) “A Test of Consumer Demand Theory Using Observations of Individual Consumer Purchases,” Western Economic Journal 11, 411-28.

Davis, Douglas, Edward Millner and Robert Reilly (2004), “Subsidy Schemes and Charitable Contributions: A Closer Look”, Experimental Economics (forthcoming).

Eckel, Catherine C. and Philip J. Grossman (2003) "Rebate vs. Matching: Does How We Subsidize Charitable Contributions Matter?” Journal of Public Economics 87, 681-701.

Eckel, Catherine C. and Philip J. Grossman (2002) “Subsidizing Charitable Giving: Further Laboratory Evidence on Rebate versus Matching” Manuscript, Virginia Polytechnic Institute and State University.

Férver, Philippe and Michale Visser (2004) “A Study of Consumer Behavior Using Laboratory Data, Experimental Economics, 7, 93-114.

Folkes, Valerie, and Rita D. Wheat, (1995) “Consumers' Price Perceptions of Promoted Products” Journal of Retailing 71, 317-28“

Harbaugh, William T., Kate Krause and Timothy R. Berry (2001) “GARP for Kids: On the Development of Rational Choice Behavior” American Economic Review 91, 1535-49.

Harrison, Glenn W., Ronald M. Harstad and E. Elisabet Rutström, (2004) “Experimental Methods and Elicitation of Values” Experimental Economics 7, 123-40.

Hoffman, E., D.J. Menkhaus, D. Chakravarti, R.A. Filed, and G.D. Whipple (1993) “Using Laboratory Experimental Auctions in Marketing Research: A Case Study of New Packaging for Fresh Beef,” Marketing Science 12, 318-338.

Kagel, John H., Raymond, C. Battalio and Leonard Green (1995) Economic Choice Theory: An Experimental Analysis of Animal Behavior. Cambridge: Cambridge University Press.

Kahneman, Daniel, Jack L. Knetsch and Richard H. Thaler (1990) "Experimental Tests of the Endowment Effect and the Coase Theorem” Journal of Political Economy 98,6, 1325-48. 


\begin{tabular}{|c|r|c|c|}
\hline $\begin{array}{c}\text { (a) } \\
\text { Problem }\end{array}$ & $\begin{array}{c}\text { (b) } \\
\text { Condition }\end{array}$ & $\begin{array}{c}\text { (c) } \\
\text { Spend (on } \\
\text { choc. bars) }\end{array}$ & $\begin{array}{c}\text { (d) } \\
\text { Hold (for } \\
\text { yourself) } \\
=\$ 5.00-\text { (c) }\end{array}$ \\
\hline BASE-33 & Each chocolate bar costs $\$ 0.33$ & \\
\hline MATCH-25 & $\begin{array}{c}\text { Each chocolate bar purchased costs } \$ 0.50 \text {. For every } \\
\text { bar purchased, you will receive an additional bar free }\end{array}$ & & \\
\hline MATCH-33 & $\begin{array}{l}\text { Each chocolate bar purchased costs } \$ 0.50 \text {. For every 2 } \\
\text { bars purchased, you will receive an additional bar free }\end{array}$ & & \\
\hline BASE-50 & Each chocolate bar costs $\$ 0.50$ & & \\
\hline REBATE-25 & $\begin{array}{c}\text { Each chocolate bar purchased costs } \$ 0.50 \text {. You will } \\
\text { receive a 50\% refund for every dollar you spend on } \\
\text { chocolate bars }\end{array}$ & & \\
\hline REBATE-33 & $\begin{array}{c}\text { Each chocolate bar purchased costs } \$ 0.50 \text {. You will } \\
\text { receive a 33\% refund for every dollar you spend on } \\
\text { chocolate bars }\end{array}$ & & \\
\hline BASE-25 & Each chocolate bar costs $\$ 0.25$ & & \\
\hline
\end{tabular}

Figure 1. Sample Allocation Decision Sheet. Note: the Problem Identifiers listed in column (a) are presented to facilitate presentation. In the experiment non-suggestive identifiers were used. Specifically, problem identifiers were, respectively, S, E, M, D, F, T and H. 


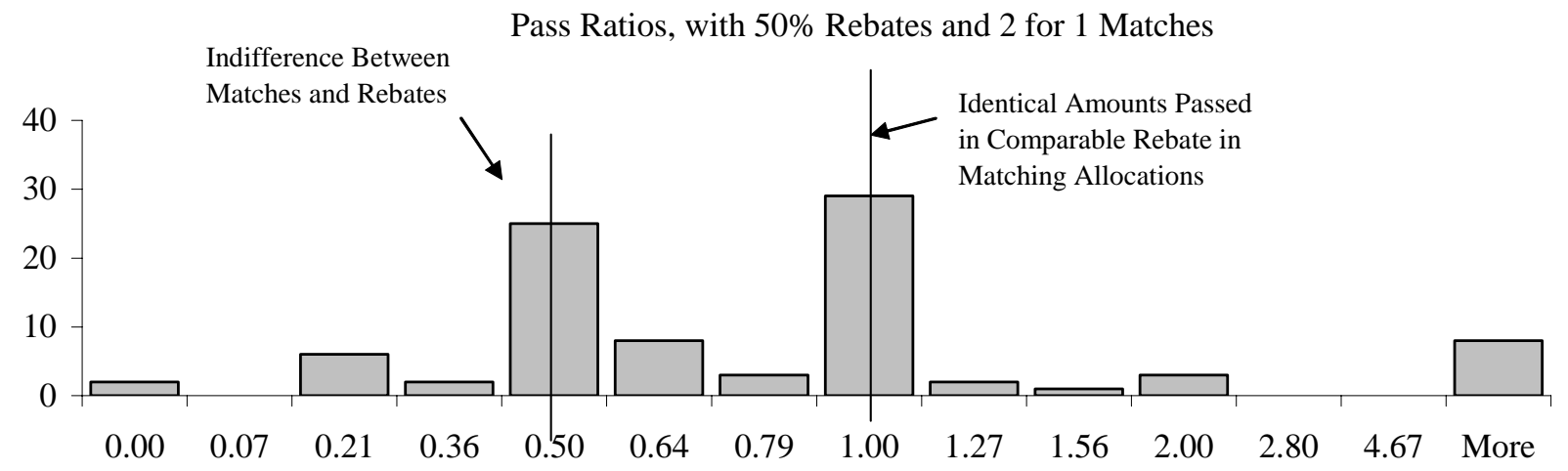

Pass Ratios, with 33\% Rebates and 3 for 2 Matches

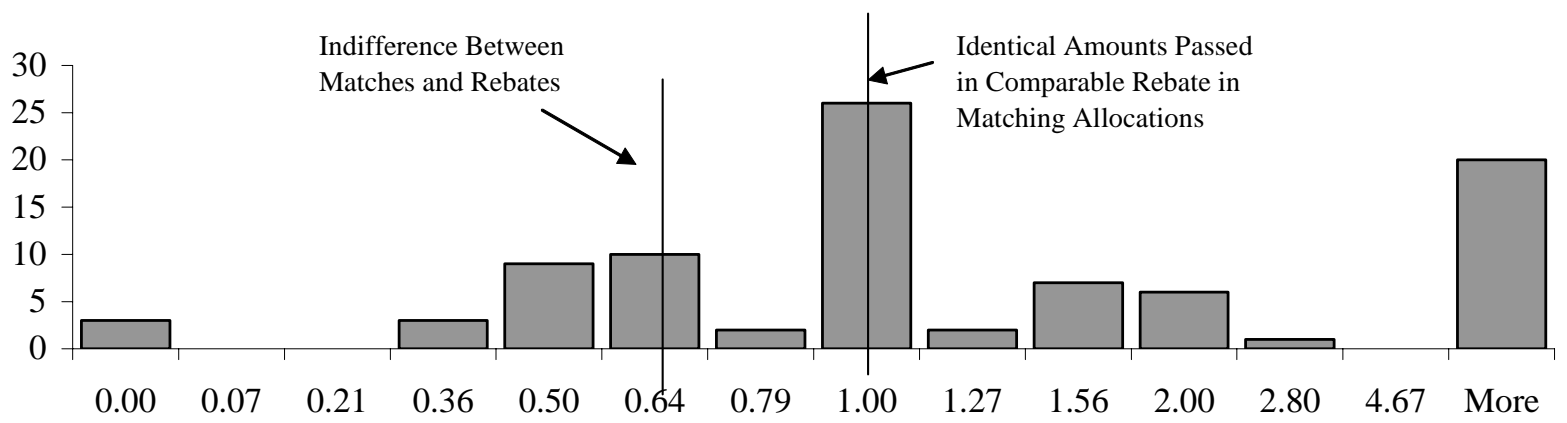

Figure 2. Pass Ratios. Key: The upper panel illustrates the distribution of Pass Ratios for individuals, under a " 2 for the price of 1 match and a " $1 / 2$ off" rebate. The lower panel illustrates comparable Pass Ratios distributions under a " 3 for the price of 2 match and a 1/3 off rebate. In each panel the Pass Ratio is the ratio of the amount passed under the matching condition to the amount passed under the comparable rebate. 


\begin{tabular}{|c|c|c|c|}
\hline \multicolumn{3}{|c|}{ Table 1. Bars Purchased: Mean (Standard Deviation) } \\
\hline \multirow{2}{*}{ Price } & \multicolumn{3}{|c|}{ Subsidy Condition } \\
& $\begin{array}{c}(1) \\
\text { None }\end{array}$ & Match & $\begin{array}{c}\text { (3) } \\
\text { Rebate }\end{array}$ \\
\hline 0.50 & 2.46 & & \\
& $(2.19)$ & & $2.75^{*}$ \\
\hline 0.33 & $3.21^{* *}$ & $3.94^{* *}$ & $(2.49)$ \\
& $(3.32)$ & $(3.11)$ & $3.60^{* *}$ \\
\hline 0.25 & $4.73^{* *}$ & $5.17^{* *}$ & $(2.64)$ \\
& $(4.12)$ & $(4.12)$ & \\
\hline
\end{tabular}

Asterisks indicate that mean purchases in the cell exceed purchases in the preceding row

* indicates $p<.10$, one tailed test. ${ }^{* *}$ indicates $p<.001$, one tailed test. For all comparisons $\mathrm{n}=89$. 


\section{Table 2 - t-tests results for Paired Differences, (Higher average)}

\begin{tabular}{|c|c|c|c|}
\hline Price & $(1)$ & $(2)$ & (3) \\
\hline & N v. M & N v. R & M v. R \\
\hline 0.33 & 0.02 & 0.10 & 0.00 \\
& $(\mathrm{M})$ & $(\mathrm{N})$ & $(\mathrm{M})$ \\
\hline 0.25 & 0.14 & 0.00 & 0.00 \\
& $(\mathrm{M})$ & $(\mathrm{N})$ & $(\mathrm{M})$ \\
\hline
\end{tabular}

$\mathrm{N}$ denotes that neither subsidy is in effect, $\mathrm{M}$ denotes that a matching subsidy is in effect, and $\mathrm{R}$ denotes that a rebate subsidy is in effect.

$p$-values are for 2-tailed tests. $\mathrm{n}=89$ 


\begin{tabular}{|c|c|c|c|}
\hline \multicolumn{3}{|c|}{ Table 3. Analysis of Non-Optimizing Pass-Ratios } \\
\hline Condition & $(1)$ & $(2)$ & $(3)$ \\
& MATCH-25 & MATCH-33 & MATCH-ALL \\
\hline REBATE-25 & REBATE-33 & REBATE-ALL \\
\hline Null Hypothesis & & & \\
\hline Equal Number of Deviations & & & \\
Deviations Above 1 & 14 & $\mathbf{3 6}$ & 50 \\
Deviations Below 1 & 21 & $\mathbf{1 9}$ & 40 \\
& & & 1.11 \\
$\chi^{2}$ (1) test statistic & 1.4 & $\mathbf{5 . 2 6}$ & 0.29 \\
p-value & 0.24 & $\mathbf{. 0 2 2}$ & \\
\hline $\begin{array}{c}\text { Symmetric Distribution of } \\
\text { Deviations above and below 1. }\end{array}$ & & & $\mathbf{0 . 4 5}$ \\
Maximum Cumulative & $\mathbf{. 5 2}$ & $\mathbf{0 . 3 9}$ & $\mathbf{( 0 . 0 0 )}$ \\
Difference & & $\mathbf{( 0 . 0 2 6 )}$ & \\
p-value & $\mathbf{( . 0 0 1 )}$ & & \\
(Kolmorgorov Smirnov, Exact) & &
\end{tabular}

Bolded entries highlight instances where $\mathrm{p}<.05$, direction not predicted.. 


\begin{tabular}{|c|c|c|}
\hline \multicolumn{3}{|c|}{ Table 4 - Relative Response Frequencies to Hypothetical Scenario Questions } \\
\hline & Scenario \#1 & Scenario \#2 \\
\hline Preference & $28 \%$ & $63 \%$ \\
\hline Matching Discount & $71 \%$ & $16 \%$ \\
Rebate Discount & $1 \%$ & $22 \%$ \\
Indifferent & & \\
\hline & & \\
\hline Justification & $9 \%(30 \%)$ & $11 \%(16 \%)$ \\
\hline Effective prices are unequal & $13 \%(43 \%)$ & $30 \%(45 \%)$ \\
Effective prices are equal & $8 \%(26 \%)$ & $25 \%(38 \%)$ \\
Averse to Rebates & $71 \%$ & $34 \%$ \\
No Justification Given &
\end{tabular}

$\mathrm{n}=102$ (One of the 103 participants did not complete the questionnaire). Italicized entries at the bottom of the table reflect percentages for the participants who gave a justification for their choices ( $n=30$ Scenario \#1 and $n=68$ in Scenario \#2). 


\section{Appendix A . Experiment Instructions,}

Because of its high quality, Ghirardelli chocolate is a delightful treat and wonderful small gift. For the Love of Chocolate, a store in Carytown, sells 1.25 oz. Ghirardelli chocolate bars for \$1.25 per bar, plus tax. Two popular varieties are Dark Chocolate and Milk Chocolate with Almonds. You are being given the opportunity to purchase your preferred combination of these two varieties under seven different conditions, using up to $\$ 5.00$ of your earnings from the preceding experiment.

For each allocation decision on the next page, you must decide how much of $\$ 5.00$ you would like to spend on chocolate bars and how much you would like to hold for yourself. Enter the amount you would like to spend on chocolate bars in column (c). Subtract this amount from $\$ 5.00$ and enter the difference as the amount you hold in column (d). Thus, the sum of the values in each row of the allocation decision sheet must sum to $\$ 5.00$. When you finish the allocation decision sheet, please raise your hand.

One participant will be selected at random. The participant selected will draw a card to determine randomly which of the seven allocation decisions will be implemented. Dollars and chocolate bars will be exchanged as determined by the choice for that allocation decision. Any refunds or free chocolate bars associated with the choice will be given to the participant with the chocolate bars purchased. If the choice involves the receipt of chocolate bars, the participant may choose Dark Chocolate bars only, Milk Chocolate with Almonds bars only, or some of each variety, as they prefer.

To clarify the consequences of the various "Conditions” explained in column (b) of your allocation decision sheet, consider the outcomes of some hypothetical choices that might be implemented.

- Suppose that the Condition for the implemented choice is "Each chocolate bar purchased costs $\$ 0.50$.” If you spend $\$ 1.50$ on chocolate bars and hold $\$ 3.50$, then you will pay $\$ 1.50$ and receive 3 bars of your choice. If you spend $\$ 2.00$ on chocolate bars and hold $\$ 3.00$, then you will pay $\$ 2.00$ and receive 4 bars of your choice.

- Suppose that the Condition for the implemented choice is "Each chocolate bar purchased costs $\$ 0.50$. You will receive a 50\% refund for every dollar you spend on chocolate bars.” If you spend $\$ 1.50$ on chocolate bars and hold $\$ 3.50$, then you will pay $\$ 1.50$ and receive a rebate of $\$ 0.75$ and 3 bars of your choice. If you spend $\$ 2.00$ on chocolate bars and hold $\$ 3.00$, then you will pay $\$ 2.00$ and receive a rebate of $\$ 1.00$ and 4 bars of your choice.

- Suppose that the Condition for the choice implemented is "Each chocolate bar purchased costs $\$ 0.50$. For every 2 bars purchased, you will receive an additional bar free.” If you spend $\$ 1.50$ on chocolate bars and hold $\$ 3.50$, then you will pay $\$ 1.50$ and receive 3 bars of your choice and 1 additional bar of your choice. If you spend $\$ 2.00$ on chocolate bars and hold $\$ 3.00$, then you will pay $\$ 2.00$ and receive 4 bars of your choice and 2 additional bars of your choice.

Do you have any questions? 